\title{
RELAÇÕES ÉTNICO-RACIAIS EM LIVROS DISTRIBUÍDOS PELO PNBE
}

\author{
Paulo Vinícius Baptista da Silva ${ }^{1}$ \\ Ana Carolina Lopes Venâncio²
}

Resumo: Artigo apresenta análise de obras do Programa Nacional Biblioteca na Escola (PNBE) vinculada aos estudos brasileiros que investigam de forma crítica a criação e difusão de formas de hierarquização social (de idade, gênero, raça e relativos à deficiência) por meio de discursos e imagens veiculadas pela literatura infanto-juvenil. O presente texto relata os resultados obtidos acerca das questões étnico-raciais nas obras analisadas.

Palavras-chave: Literatura infanto-juvenil. Diversidade. Relações étnico-raciais.

\section{ETHNIC-RACIAL RELATIONSHIPS IN BOOKS DISTRIBUTED BY PNBE}

\begin{abstract}
Article presents works by analyzing the National Library Program in School (PNBE) linked to Brazilian studies investigating critically the creation and diffusion of forms of social hierarchy (age, gender, race and on disability) through speeches and images carried by the children's literature. This paper reports the results obtained about the ethnic and racial issues in the analyzed works.

Keywords: infant-juvenile literature. Diversity. Ethnic-racial relations.
\end{abstract}

\section{Introdução}

Este artigo apresenta análise específica sobre relações étnico-raciais, a partir de uma pesquisa de mestrado onde foi empreendido estudo que visou à análise da diversidade em obras que compunham os acervos do Programa Nacional Biblioteca na Escola (PNBE), voltado aos educandos do $1^{\circ}$ ao $5^{\circ}$ ano do Ensino Fundamental de 09 anos, selecionados no edital do ano de 2007, para distribuição e uso em 2008, sob financiamento do Fundo Nacional de Desenvolvimento da Educação (FNDE). Naquele ano foram distribuídos para as escolas acervos de 20 livros, em função do porte das escolas entre 1 e 5 acervos. Os acervos eram compostos por livros previamente selecionados e com variedade de gênero textual, em forma de prosa e de poesia. Optou-se por analisar um acervo de 20 livros distribuído a uma escola da rede mu-

1 Professor do Programa de Pós-Graduação em Educação da Universidade Federal do Paraná, pesquisador do Núcleo de Estudos Afro-Brasileiros (NEAB-UFPR) na mesma universidade. Pesquisador do CNPQ. E-mail: pauloviniciusufpr@gmail.com.

2 Doutoranda do Programa de Pós-Graduação em Educação da Universidade Federal do Paraná. Professora e pedagoga da rede pública de ensino. Contadora de Histórias. E-mail: aclv_ana_carol@hotmail.com. 
nicipal de Curitiba, considerando tal acervo como amostra do total de até 100 livros distribuídos para escolas com mais de mil alunos( $\left.\mathrm{as}^{3}\right)$.

A análise adotou abordagem qualitativa e quantitativa. Para a análise qualitativa foi realizada a leitura completa dos livros, preparada uma sinopse dos mesmos, destacados pontos de relevância para a compreensão das apresentações de pessoas com deficiência e das relações de gênero, étnico-raciais e de idade.

$\mathrm{Na}$ análise quantitativa os livros foram submetidos à análise de conteúdo enfocando os personagens - suas características e atributos. A grade de análise utilizada no estudo de conteúdo foi uma adaptação da grade utilizada por Rosemberg (1985) e posteriormente adaptada por Silva (2008).

O processo de caracterização do perfil das personagens subsidiou a investigação das formas de criação e recriação de "personagens-tipo", analisando-se a criação de modelos — personagens ideais — que poderiam servir como pautas de "conduta" e, paralelamente, se considerou a difusão de tais modelos culturais por meio dos programas de Governo voltados à infância e adolescência. A pesquisa, portanto, se vinculou aos estudos brasileiros que analisam de forma crítica a criação e difusão de formas de hierarquização social (relativos à deficiência, raça, gênero e idade) por meio de discursos e imagens veiculados pela literatura infantojuvenil. Para este artigo destacamos, entre os diferentes eixos analisados, as relações étnicoraciais.

A análise esteve atenta em que medida os livros que compunham os acervos distribuídos pelo MEC em 2008 valorizavam a diversidade ou, pelo contrário, atuavam para apresentar padrões hierarquizados, contribuindo no processo de estigmatização de personagens desviantes desse padrão. Objetivou-se construir um panorama de como as políticas públicas - no presente caso políticas especificamente voltadas ao fomento da leitura e provimento de bibliotecas escolares — podem influenciar no processo de formação da identidade e personalidade de alunos das redes públicas de ensino.

O estudo desenvolvido apoiou-se numa perspectiva crítica de análise sobre as políticas educacionais e culturais, apoiando-se especialmente nas pesquisas brasileiras sobre deficiên-

3 O texto passa a adotar o genérico masculino na continuidade, como forma de aliviá-lo. 
cia e diversidade de gênero, raça e idade na literatura infanto-juvenil. Entre as perspectivas teórico-metodológicas, tem uma contribuição diferenciada os estudos de Rosemberg (1985) sobre a literatura infanto-juvenil, especificamente a concepção do papel desta literatura como discurso ideológico, espaço de criação e reprodução de desigualdades de idade, gênero e raça e a compreensão da complexidade e não-linearidade das interações entre os diferentes eixos de desigualdade (ROSEMBERG, 1985; 2012).

A hipótese de pesquisa foi de que o discurso midiático e o discurso difundido pelos livros infanto-juvenis e didáticos têm ficado, em geral, alheios à apresentação da diversidade, divulgando conceitos legitimadores de hierarquias sociais ao apresentar "personagens-tipo", com características que privilegiam determinados traços, sendo a diferença discursivamente construída como motivo de estranhamento e não como elemento constitutivo da humanidade.

O olhar sobre as relações étnico-raciais privilegiado no artigo articula-se as pesquisas do NEAB-UFPR que se voltam aos modelos culturais estabelecidos por livros dirigidos à infância, na literatura infanto-juvenil (VENÂNCIO, 2009; OLIVEIRA, 2010; ARAÚJO, 2010, 2015; ARAÚJO e SILVA, 2012; SILVA, 2014).

Estas pesquisas dialogam fortemente com as desenvolvidas pelo Núcleo de Estudo de Relações de Gênero, Raça e Idade (NEGRI) e, em função da importância do trabalho de Rosemberg para a análise elaborada neste artigo, estão dispostos no Quadro 1 uma síntese dos resultados da pesquisa coordenada pela autora sobre modelos culturais na literatura infantojuvenil brasileira (ROSEMBERG, 1985), na qual foi analisada ampla amostra de livros de literatura infanto-juvenil, publicados entre 1955 e 1975; como também de uma tese e uma dissertação orientados pela mesma (PISA, 1998; BAZILLI, 1999). 
Quadro 1 - Síntese de resultados de pesquisas de Rosemberg sobre relações raciais na LIJ

\begin{tabular}{|c|c|}
\hline $\begin{array}{l}\text { Rosemberg } \\
\text { (1985) }\end{array}$ & $\begin{array}{l}\text { - Estereotipia da ilustração que se refere à personagem negra e indígena. } \\
\text { - Tratamento diferencial dado a grupos brancos e não-brancos. Quase ausência de persona- } \\
\text { gens indígenas e negras. Melhor caracterização de personagens brancas. } \\
\text { - Recriação da realidade social via literatura infanto-juvenil, com a simbologia do veículo se } \\
\text { utilizando tanto do texto quanto da imagem para reforçar ideologias. } \\
\text { - Discriminação contra grupos não-brancos: Aparece tanto de forma aberta quanto de forma } \\
\text { latente. A negação ao direito à existência humana é a forma latente de preconceito que } \\
\text { mais se destaca: o branco é o representante da espécie. } \\
\text { - Associação da cor negra a personagens más. Cor negra associada a castigo. Em contrapar- } \\
\text { tida, valorização da cor branca. } \\
\text { - Indígenas e negros comparados a animais. Maior frequência de personagens antropomorfi- } \\
\text { zadas associadas à cor negra. } \\
\text { - Personagens brancas, apesar de sua pluralidade, não perdem sua individualidade. Persona- } \\
\text { gens não-brancas sem individualidade e unicidade. Mulher negra não existe na ilustração. } \\
\text { - O branco tem, mais do que o não-branco, nome, sobrenome, apelido, maior diversidade } \\
\text { profissional e maior número de categorias comportamentais. O acabamento literário da } \\
\text { personagem não-branca é menos perfeito. }\end{array}$ \\
\hline & $\begin{array}{l}\text { - Sociedades racistas engendram a formação de autoras com perspectivas estereotipadas e } \\
\text { preconceituosas. } \\
\text { - Textos e imagens estereotipados no tocante à literatura destinada à criança e ao jovem. } \\
\text { Estereótipos como produtos das expectativas sociais neles depositadas e como decorrência } \\
\text { de processos de categorização social. Constatação de discriminação valorativa e compor- } \\
\text { tamental. } \\
\text { - Percepção de grupo, coletividade e não de "indivíduo" com características próprias. Ne- } \\
\text { gros como "multidão". } \\
\text { - Verificação de relações assimétricas, com hierarquizações sociais advindas de movimentos } \\
\text { de categorização individual ou grupal baseados em estereótipos. } \\
\text { - Formas de racismo baseadas em gênero e classe social. Sexualidade e feminilidade racial- } \\
\text { mente específicas. Libido da personagem negra exacerbada. } \\
\text { - Estabelecimento de modelos de conduta. } \\
\text { - Texto como informante de dinâmicas sociais que nele transparecem e são cristalizadas, } \\
\text { muitas vezes, através de estereótipos presentes nas imagens. }\end{array}$ \\
\hline & $\begin{array}{l}\text { - Apesar da grande mobilização de movimentos sociais, permanece discurso racista na lite- } \\
\text { ratura infanto-juvenil. Pequenas mudanças são observadas, mas sem alterações significati- } \\
\text { vas na produção destinada ao público infantil e juvenil. } \\
\text { - Silêncio presente na ausência de informações acerca de personagens negras. Observação } \\
\text { de marcas ideológicas na literatura infanto-juvenil. } \\
\text { - Homem branco adulto como representante da espécie. } \\
\text { - Manutenção de relações de dominação pela naturalização das relações de opressão. } \\
\text { - Utilização de formas simbólicas na representação da personagem negra que é, frequente- } \\
\text { mente, desprivilegiado ficcionalmente. Quando da apresentação dos atributos negros, uso } \\
\text { de sentido depreciativo constrói personagens de forma negativa. Pouco relevo no desen- } \\
\text { volvimento da personagem não-branca na trama. } \\
\text { - Estereotipia nas ilustrações. } \\
\text { - Tendência de produzir histórias destinadas ao leitor branco, mantendo-se os privilégios } \\
\text { ficcionais desse segmento étnico. }\end{array}$ \\
\hline
\end{tabular}

A tese de Pisa (1998) desenvolve a discussão proposta por Rosemberg (2012) sobre a assincronia entre as desigualdades sociais em diferentes eixos. Discutindo a criação de personagens negras por autoras brancas, revela como ao mesmo tempo em que as trajetórias das autoras e as personagens por elas criadas tem traços emancipatórias no eixo de gênero, ancoram-se em padrões hierárquicos e estigmatizantes em suas construções de personagens femininas negras. 
A dissertação de Bazilli (1999) faz parte de um grupo de dissertações (ESCANFELLA, 1999; NOGUEIRA, 2001) que buscaram atualizar a pesquisa coordenada por Rosemberg (1985) sobre modelos culturais dirigidos à infância, utilizando a mesma metodologia para analisar amostra de livros de literatura infanto-juvenil editados ou reedidatos entre 1975 e 1994, ou seja, atualizando em 20 anos o estudo original.

Tais resultados são importantes para a discussão apresentada neste artigo, visto que a metodologia de análise foi orientada por estes estudos anteriores (ROSEMBERG, 1985; BAZILLI, 1999) utilizando uma grade de análise destes atualizada, o que possibilita um cotejamento de resultados com grande confiabilidade.

\section{Análise de dados catalográficos}

Definiu-se proceder à análise de um acervo, de forma qualitativa e quantitativa, contemplando cada obra em sua totalidade. O Quadro 2 apresenta a relação das obras do acervo analisado.

Quadro 2 - Obras do acervo analisado

\begin{tabular}{|l|l|}
\hline \multicolumn{1}{|c|}{ TÍTULO } & \multicolumn{1}{|c|}{ ANO DE PUBLICAÇÃO } \\
\hline 25 Anos do Menino Maluquinho & $2006 / 5^{\mathrm{a}}$ Edição \\
\hline A menina da varanda & $2007 / 6^{\mathrm{a}}$ Edição \\
\hline À toa, à toa & $2008 / 5^{\mathrm{a}}$ Edição \\
\hline As coisas que a gente fala & $2005 / 2^{\mathrm{a}}$ Edição \\
\hline Brincadeiras & $2007 / 3^{\mathrm{a}}$ Tiragem \\
\hline Cantarim de Cantará & 2007 \\
\hline Catando piolhos, contando histórias & 2006 \\
\hline Contos de animais do mundo todo & 2003 \\
\hline Da cabeça aos pés & $2002 / 3^{\mathrm{a}}$ Edição \\
\hline Dadá e Dazinha & $2007 / 3^{\mathrm{a}}$ Edição \\
\hline Entre os bambus & $2008 / 2^{\mathrm{a}}$ Edição \\
\hline Felpo Filva & $2006 / 1^{\mathrm{a}}$ Edição \\
\hline O menino inesperado & $2007 / 5^{\mathrm{a}}$ Edição \\
\hline Livro de Papel & $2001 / 1^{\mathrm{a}}$ Edição \\
\hline Lampião e Maria Bonita: O rei e a rainha do cangaço & $2008 / 1^{\mathrm{a}}$ Edição \\
\hline O vôo supersônico da galinha Galatéia & $2007 / 2^{\mathrm{a}}$ Edição \\
\hline PíppiMeialonga & $2001 / 1^{\mathrm{a}}$ Edição \\
\hline Rei Artur e os cavaleiros da Távola Redonda & $16^{\mathrm{a}}$ Reimpressão \\
\hline Ulomma: A casa da beleza e outros contos & $2007 / 1^{\mathrm{a}}$ Edição \\
\hline Você viu meu pai por aí? & 2006 \\
\hline
\end{tabular}

Fonte: Tabulações dos autores

$\mathrm{O}$ corpus da pesquisa advém de publicações de editoras que são empresas de médio e grande porte. A produção dos livros se deu exclusivamente no eixo Rio - São Paulo, fato já observado em pesquisas anteriores (cf. ROSEMBERG, 1985, BAZILLI, 1999, ESCANFEL- 
LA, 1999, 2006). As editoras foram, neste estudo, concebidas como "espaço estruturado, hierarquizado, que possui um centro, posições intermediárias, uma periferia e um lado de fora", em concordância com Dalcastagnè (2005, p. 22-23), entendendo-se que o mercado editorial influi diretamente na produção e divulgação da literatura infanto-juvenil, segundo critérios pré-estabelecidos, dentro de uma perspectiva de mercado. Observa-se que não houve "edição caseira" de obras do acervo do PNBE, com as editoras selecionadas tendo reconhecimento nacional. As editoras têm poder para legitimar discursos, reforçam ou alteram conceitos e práticas, sendo capazes de interferir de maneira privilegiada nas próprias regras que estruturam a sociedade (ao interferirem nas relações entre grupos). Nesse prisma, fica implícita uma relação de mútuo benefício - com os autores e suas obras transferindo capital simbólico para a editora, mas, em contrapartida, recebendo o prestígio que ela já acumulou (cf. DALCASTAGNÈ, 2005, p. 23). No presente estudo fica clara a determinação dos editais sobre a produção literária, com os critérios estabelecidos para formação dos acervos movimentando o mercado editorial de maneira a promover maiores vendagens explicitando-se, igualmente, a dinâmica social e econômica por detrás das ações das editoras.

Referente à autoria, os autores das obras foram todos adultos, em sua maioria brancos (17 brancos - 2 negros - 1 indígena, dados no Quadro 3), com equilíbrio na proporção de homens e mulheres. Percebe-se que a inclusão de autores negros e indígenas refere-se ao movimento de valorização da diversidade étnico-racial do povo brasileiro. Observa-se que os próprios representantes desses grupos étnico-raciais têm sido, em geral, seus porta-vozes. É interessante notar, nesse movimento de legitimação de discursos, que 3 (três) obras do acervo privilegiaram a temática do negro e do indígena. Podemos colocar como hipótese que a atuação da SECADI ${ }^{4}$, secretaria do MEC responsável por políticas educacionais para a diversidade, pode ter sido atuante para tal.

Com relação aos ilustradores, a maioria deles é do sexo feminino, de cor branca, idade adulta (5 homens — destes, 2 negros / 13 mulheres — destas, 1 negra). Ou seja, as mulheres ocuparam um espaço maior que os homens na produção, tendo uma proporção pouco maior de autoras e uma diferença mais significativa como ilustradoras. O quadro 3 transcreve os nomes e a cor-etnia (heteroclassificação) dos autores e ilustradores.

\footnotetext{
4 Secretaria de Educação Continuada, Alfabetização, Diversidade e Inclusão, doravante referida pela sigla.
} 
O perfil do autor(a) ficou presentemente caracterizado como de pessoas brancas, aproximando-se ou entrando na meia idade, com diploma superior, morando no eixo Rio - São Paulo, com franca similaridade com a pesquisa de Rosemberg (1985), Bazilli (1999), Escanfella (1999, 2006), Nogueira (2001) e Dalcastagnè (2005). Quase todos os autores têm publicações anteriores, dedicando-se eminentemente à literatura infanto-juvenil.

Por um lado observa-se que a entrada de obras que valorizam a indígenas e a negros se deu pela via de autores e ilustradores que apresentam o discurso desde dentro, ou seja, passam a estar presentes o indígena e o negro como sujeitos de enunciação (DUARTE, 2008). Por outro lado, a hegemonia branca permanece, tanto em autores quanto à ilustradores. Tal ocorrência pode ser interpretada como manifestação, mesmo de forma latente, que se escreve para um público branco, com seus representantes tendo maiores condições de escrever sobre os temas que interessam a esse público em especial.

Quadro 3 - Listagem de autores(as) e ilustradores(as)

\begin{tabular}{|l|l|l|l|}
\hline \multicolumn{1}{|c|}{ Autores (as) } & \multicolumn{1}{c|}{ Cor/Etnia } & \multicolumn{1}{c|}{ Cor/Etnia } \\
\hline Ziraldo & Branco & Ziraldo & Branco \\
\hline Léo Cunha & Branco & Nelson Cruz & Negro \\
\hline João Proteti & Branco & Marília Cotomacci & Branca \\
\hline Ruth Rocha & Branca & Mariana Massarani & Branca \\
\hline Kátia Kanton & Branca & Kátia HarumiTerasaka & Branca \\
\hline Sylvia Orthof & Branca & Mariana Massarani & Branca \\
\hline Daniel Munduruku & Indígena & Mate & Branca \\
\hline Naomi Adler & Branca & Amanda Hall & Branca \\
\hline Marilda Castanha & Branca & Marilda Castanha & Branca \\
\hline Luiz Antônio Aguiar & Branco & Graça Lima & Branca \\
\hline Edna Bueno & Branca & SUPPA & Branca \\
\hline Eva Furnari & Branca & Eva Furnari & Branca \\
\hline Liliana Iacocca & Branca & Rosinha Campos & Branca \\
\hline Ricardo Azevedo & Branco & Ricardo Azevedo & Branco \\
\hline Elisa Lucinda & Negra & Graça Lima & Branca \\
\hline Cláudio Fragata & Branco & Cláudio Martins & Branco \\
\hline Astrid Lindgren & Branca & Michael Chesworth & Branco \\
\hline Márcia Willians & Branca & Márcia Willians & Branca \\
\hline Sunday Ikechukwu Nkeechi & Negro & Denise Nascimento & Negra \\
\hline Charles Kiefer & Branco & Maurício Veneza & Negro \\
\hline
\end{tabular}

Fonte: Tabulações dos autores

Tomamos o fato de autores brancos, indígenas ou negros não como determinantes exclusivos de sua produção, ou de que essa produção seja livre de estereótipos e necessariamente promova a diversidade étnico-racial. Em análise da literatura infantil que tem temática afro ou personagens negras principais e é voltada para a criança pequena, observamos que não o- 
correu correlação entre a cor-etnia de autores e a qualidade das obras em termos de valorização étnico-racial (ARAÚJO e SILVA, 2012).

No entanto, não é variável a ser desconsiderada e pode ser atuante na construção de personagens, como revela análise de Piza (1998) sobre a construção de personagens femininas negras por autoras brancas. O pertencimento étnico-racial dos autores é compreendido como variável que pode ser significativa, como possibilidade de que as vozes, os valores, os modos de vida, diferentes aspectos da cultura, angústias e anseios ou, por outro lado, realizações e alegrias, entrem como marcas em sua produção cultural, em seus discursos. Além disso, como possibilidade de identificação e de reconhecimento da diversidade pelos leitores de diferentes grupos étnico-raciais.

No caso específico dos livros analisados, observa-se que as duas únicas obras que privilegiaram a ideia da diversidade foram "Ulomma, a casa da beleza e outros contos" e "Catando piolhos, contando histórias", a primeira escrita por autor negro, sobre contos africanos, a segunda de Daniel Munduruku, representante indígena e militante, discorrendo sobre costumes de sua nação.

Outra obra de autora negra do acervo analisado é "O menino inesperado", obra que debate de maneira lúdica sobre o papel do medo e a importância de seu enfrentamento e superação.

\section{Análise de dados das personagens}

A unidade de análise escolhida foi a personagem, tomado como referência por meio da definição de Rosemberg (1985). Foram contados, na análise quantitativa, 60 personagens na capa, 808 na ilustração (interior da obra) e 7.259 no texto (descrição da personagem na narrativa), com predominância de personagens individualizadas $(96,7 \%, 79,1 \%$ e 80,2\%, respectivamente), de natureza humana $(86,7 \%, 50,1 \%$ e $67,1 \%)$, de sexo masculino $(66,7 \%, 46,3 \%$ e $42,4 \%)$ e de cor branca $(66,7 \%, 38,9 \%$ e $42,4 \%)$, com as crianças tendo sido maioria das personagens descritas no texto ( $32 \%$ de personagens infantis contra $30,4 \%$ de adultos).

A alta frequência de personagens humanas, com equivalente ficcional de pessoa, facilitou a inferência de processos de discriminação referentes aos atributos ora em estudo, pois o universo ficcional se aproximou do contexto social humano. Tal fato permitiu confiabilidade na análise sobre as personagens e suas características, sobre determinadas escolhas em detri- 
mento de outras, principalmente pelo silêncio voltado a certos grupos humanos nos quais se observa existência de "diferença(s)" lida como "desvio".

Os resultados gerais obtidos corroboraram estudos anteriores, mantendo prevalência de personagens brancas e do sexo masculino. Contudo, verificou-se mudança na relação etária, observando-se maior número de personagens crianças, mesmo que se mantenham relações de subalternidade da criança em relação ao personagem do adulto.

$\mathrm{Na}$ análise do eixo cor-etnia do total de 7.259 personagens identificadas nos textos, foram classificadas como brancas 3.077 (42,4\%), como pretas ou pardas $448(6,1 \%)$, como indígenas $530(7,3 \%)$ e como amarelas $43(0,6 \%)$. As categorias outras cores, com 1.811 casos $(24,9 \%)$ e indeterminados com $1.350(18,6 \%)$ apresentaram proporções significativas.

Observa-se a sub-representação de personagens negras(os) que foram 6,1\% das personagens do acervo, ao passo que mais de $50 \%$ da população brasileira é negra. Utilizamos a "taxa de branquidade" proposto por Rosemberg (1985) para efeito comparativo com outras pesquisas. No acervo analisado o índice foi de 6,9 (significa que cada personagem negro correspondeu a 6,9 personagens brancos). Esse índice foi mais alto que o de 3,6 detectado na amostra de Bazilli (1999). Ou seja, mesmo com políticas de promoção de igualdade racial em discussão e implantação e com possível busca de interferência da SECADI nas políticas do livro (ARAÚJO, 2013) a desigualdade se manteve alta quando comparada com estudos anteriores. Analisando uma amostra de livros distribuídos pelo PBNE do mesmo ano, 2008, para a Educação Infantil, Oliveira (2010) encontrou uma taxa de branquidade muito similar, de 6,8. Pode-se interpretar tal resultado como indicativo da solidez da "branquidade normativa", do branco como representante da espécie, fato manifesto nos discursos da literatura infantojuvenil distribuída pelo PNBE, a despeito das diversas críticas e mobilizações sociais. Observa-se, portanto, que a branquidade ainda se faz norma, apesar dos movimentos reivindicatórios, de leis que determinam a exploração da riqueza da cultura africana (BRASIL, 2003) e frente a atuação de órgãos como a SECADI.

No caso da população indígena não se pode falar de sub-representação, pois o percentual de personagens no acervo, 7,3\%, é maior que o percentual de indígenas na população brasileira (cerca de 1\%). A inserção nos acervos do PNBE de obras que valorizam a população indígena tem como resultado a não sub-representação de personagens indígenas. Uma discussão mais detalhada sobre tais obras será realizada posteriormente. 
A seguir dispõem-se no Quadro 4 resultados relativos ao cruzamento de atributos de personagens brancas em comparação com personagens negras (agrupamento de pretas e pardas). Na última coluna estão as taxas de branquidade. Como a taxa de branquidade na amostra foi de 6,9, valores abaixo desse indicam uma menor desigualdade entre brancos e negros no item específico e valores maiores indicam um aumento na desigualdade.

Quadro 4 - Cruzamento atributo cor-etnia com demais itens de análise

\begin{tabular}{|c|c|c|c|c|}
\hline Itens de análise & Cor/Etnia & Porcentagem & $\begin{array}{c}\text { Valor absoluto } \\
\mathbf{N}=7259\end{array}$ & Taxa de branquidade \\
\hline Relações etárias & $\begin{array}{l}\text { Criança } \\
\text { Branca } \\
\text { Preta / parda } \\
\text { Adulto } \\
\text { Branco } \\
\text { Preto / pardo }\end{array}$ & $\begin{array}{l}64,2 \% \\
13 \% \\
81,5 \% \\
11,3 \%\end{array}$ & $\begin{array}{l}1974 \\
300 \\
224 \\
31\end{array}$ & $\begin{array}{l}6,6 \\
7,2\end{array}$ \\
\hline Gênero & $\begin{array}{l}\text { Sexo Masculino } \\
\text { Branco } \\
\text { Preto e pardo } \\
\text { Sexo Feminino } \\
\text { Branco } \\
\text { Preto / pardo }\end{array}$ & $\begin{array}{l}35,8 \% \\
8,9 \% \\
66,8 \% \\
5,7 \%\end{array}$ & $\begin{array}{l}962 \\
256 \\
1934 \\
165\end{array}$ & $\begin{array}{l}3,8 \\
11,7\end{array}$ \\
\hline $\begin{array}{l}\text { Personagem Princi- } \\
\text { pal }\end{array}$ & $\begin{array}{l}\text { Branco } \\
\text { Preto / pardo }\end{array}$ & $\begin{array}{l}60 \% \\
7,9 \%\end{array}$ & $\begin{array}{l}2414 \\
316\end{array}$ & 7,6 \\
\hline Narrador & $\begin{array}{l}\text { Narrador: } \\
\text { Branco } \\
\text { Preto / pardo }\end{array}$ & $\begin{array}{l}34 \% \\
10,5 \% \\
\end{array}$ & $\begin{array}{l}84 \\
26 \\
\end{array}$ & 3,2 \\
\hline Ação própria & $\begin{array}{l}\text { Branco } \\
\text { Preto / pardo }\end{array}$ & $\begin{array}{l}49,6 \% \\
6,2 \% \\
\end{array}$ & $\begin{array}{l}3003 \\
373 \\
\end{array}$ & 8,1 \\
\hline Profissão & $\begin{array}{l}\text { Branco } \\
\text { Preto / pardo }\end{array}$ & $\begin{array}{l}19,7 \% \\
16,2 \% \\
\end{array}$ & $\begin{array}{l}393 \\
323\end{array}$ & 1,2 \\
\hline $\begin{array}{l}\text { Valor do persona- } \\
\text { gem: Positivo ou } \\
\text { neutro }\end{array}$ & $\begin{array}{l}\text { Branco } \\
\text { Preto e pardo }\end{array}$ & $\begin{array}{l}52,9 \% \\
3,4 \%\end{array}$ & $\begin{array}{l}2760 \\
168\end{array}$ & 16,4 \\
\hline $\begin{array}{l}\text { Relações de paren- } \\
\text { tesco }\end{array}$ & $\begin{array}{l}\text { Branco } \\
\text { Preto / pardo }\end{array}$ & $\begin{array}{l}67,3 \% \\
8,3 \%\end{array}$ & $\begin{array}{l}2475 \\
305\end{array}$ & 8,1 \\
\hline
\end{tabular}

Fonte: Tabulações dos autores

No que se refere a personagens crianças e personagens adultos as variações foram pequenas, um pouco menor para crianças $(6,6)$ que a média geral e um aumento discreto $(7,2)$ para adultos. No que se refere ao sexo dos personagens o resultado foi de diminuição da taxa de branquidade relativa a personagens masculinos negros $(3,8)$ e aumento relativo a personagens femininas negras $(11,7)$. Na amostra de Bazilli as taxas de branquidade sugeriam "uma tendência cumulativa: os diferenciais aumentam para atributos socialmente valorizados e/ou discriminados. Assim, elas são mais altas para homens que para mulheres, para adultos que para crianças" (BAZILLI, 1999, p. 84). Na literatura brasileira contemporânea analisada por Dalcastagnè houve pouca visibilidade das personagens femininas e menor ocorrência quanto 
às mulheres negras, o que sugere a ideia de que há um "padrão" no processo de criação das personagens, com cada desvio ocorrido reduzindo a chance de ocorrência de outro (DALCASTAGNÈ, 2005, p. 46). No acervo analisado o resultado foi diferente, pois a elevação relativa a personagens adultos foi de pequena magnitude e em relação ao sexo dos personagens observou-se uma inversão relativa à hierarquia, com a presença relativamente maior de personagens femininas negras em relação a personagens masculinos negros. Essa presença mais significativa de mulheres negras parece ter relação com a obra do acervo de valorização da cultura afro "Ulomma", na qual as personagens femininas estão bastante presentes.

Os outros resultados apontam características indicativas de complexidade das personagens. Por um lado temos a indicação de profissões com grande diminuição da desigualdade entre brancos e negros e tendendo à igualdade $(1,2)$ e uma presença de narradores negros ainda em desvantagem em relação a brancos, mas com desigualdade $(3,2)$ abaixo da metade da frequência de personagens. Por outro, se observa incremento na desigualdade no que diz respeito à personagem principal $(7,6)$, personagens com ação própria $(8,1)$, relações de parentesco $(8,1)$ e de maior monta para personagens valorizados ou neutros $(16,4)$.

Tais resultados mais uma vez divergem dos resultados de Bazilli (1999) nos quais o tratamento textual dispensado ao personagem branco foi mais elaborado que o dispensado aos não-brancos. A personagem branca aparecia como personagem individualizada, protagonista, transpondo-se para as narrativas a importância do segmento racial branco na sociedade brasileira. Na amostra do PNBE constatou-se tênue mudança, com a complexidade de personagens brancas em relação a personagens negras sendo menos expressiva do que a captada em outros estudos. Os dados deste estudo sobre o PNBE de 2008 para o Ensino Fundamental também diferem dos dados de Oliveira (2010) com amostra do PNBE 2008 para Educação Infantil, pois no caso da amostra dirigida ao pequenos além da sub-representação já aludida, os dados reiteram a menor complexidade de personagens negras em relação a personagens brancas. No presente estudo a mudança diz respeito à melhor elaboração da personagem do negro quando este aparece na narrativa, tendo, no acervo ora analisado, relações de parentesco mais elaboradas, fato pouco usual, visto que pesquisas anteriores apontavam uma "proibição tácita" quanto à representação da família negra, fosse em livros didáticos, infanto-juvenis ou outros discursos midiáticos (cf. SILVA, 2008, SILVA, SANTOS e ROCHA, 2007).

Novamente a hipótese explicativa é uma forma operacional que observamos em diversos acervos, a presença de pelo menos um livro de valorização da cultura afro e um de valori- 
zação da cultura indígena em cada acervo. Todavia, apesar das mudanças verificadas, o negro em situação de protagonismo teve ocorrência mínima, com uma única exceção referente ao livro presente no acervo de forma a contemplar a diversidade. Reitera-se, todavia, que a presença dessa obra não garantiu um tratamento igualitário, somente atenuou a diferença de complexidade entre personagens brancas e negras em relação à captada em outros estudos.

$\mathrm{Na}$ presente amostra a desigualdade manteve-se, pois para cada personagem narrador negro ocorreram 3,2 personagens narradores brancos. Dessa forma, a presença de uma obra de valorização da cultura afro determinou que a narração por personagem negro(a) passasse a existir, mesmo não superando relações de assimetria historicamente verificadas.

Outro resultado que apresentou índices melhores no acervo analisado diz respeito a relações familiares. Embora a taxa de branquidade verificada seja um pouco acima da média $(8,1)$, em outros estudos, personagens negros com relações familiares praticamente inexistiam. No entanto, aponta-se que esta melhor elaboração da família negra ainda não preencheu todas as lacunas no tocante ao respeito à identidade do negro. A filiação e outras relações de parentesco não estão, ainda, explicitadas na narrativa e não foram visualizadas nas ilustrações.

\section{Análise qualitativa}

Encontramos entre as 20 obras do acervo analisado duas que tomam a temática indígena como principal: "você viu meu pai por aí?" e "Catando piolhos, contando histórias". O fato de encontrarmos duas obras com a temática indígena no acervo é um indicador favorável e pode ser interpretado como um possível reflexo de busca de políticas de diversidade pelo MEC no período.

Por outro lado, observa-se que os personagens principais das obras do acervo foram, hegemonicamente, personagens humanos de cor branca, com exceção das obras da "cota da diversidade".

A análise dos personagens do livro "Você viu meu pai por aí?" revela alguns aspectos internos que podem ser interpretados como contraditórios. Apesar de referir-se a luta de indígenas e brancos por terras, discorrendo acerca do confinamento do indígena em reservas e sobre a negação de sua cultura, pode tanto contribuir no debate sobre o indígena na sociedade atual quanto apresentar uma visão de estereótipo, caso a leitura do livro não tenha cunho críti- 
co e análise mais criteriosa. O personagem principal foi construído no discurso como militante e, ao mesmo tempo, "homem fraco", com o filho tendo encontrado o pai bêbado, caído na rua, por ter perdido uma audiência sobre disputa de terras.

Por outro lado, direcionando uma leitura crítica, tanto das imagens quanto do texto, pode-se, por meio dessa obra, desvendar-se uma realidade de difícil enfrentamento e muitas vezes não discutida, na qual o indígena tem seus direitos negados e se vê privado de sua dignidade. Assim, apesar de abordar a temática indígena, a obra pode reforçar estereótipos dependendo da interpretação do leitor. Também cabe ressaltar que a obra ora referida desvela o cotidiano do indígena de maneira real, com o indígena brasileiro se vendo as voltas com constantes lutas e frustrações no que refere-se à defesa de suas terras e de sua cultura, com o alcoolismo, o desemprego e a vulnerabilidade social propiciados pelo descaso governamental sendo problemas atuais e de solução ainda pouco visível.

A análise permite afirmar que os personagens negros e indígenas têm tido menor elaboração no seu processo de criação, havendo menor número de informações sobre sua personalidade, costumes e relações dentro da trama. O livro "Catando piolhos, contando histórias" foi uma exceção à regra, visto que o autor, Daniel Munduruku, conta um pouco de sua própria história no cotidiano de sua nação indígena, ressaltando de forma mais elaborada tradições familiares e costumes de sua etnia. O livro tem uma narrativa em primeira pessoa a partir da qual o narrador insere diversas histórias sobre o cotidiano de seu povo, elementos das relações entre os familiares e a comunidades Munduruku, a valorização do contar histórias, dos mais velhos, das descobertas e do cuidado com o meio ambiente, dos ensinamentos tradicionais e míticos. Estamos em acordo com Bonin (2012) que a narrativa realiza um deslocamento em relação às histórias sobre os indígenas que ao longo do século XX povoaram os livros de literatura infanto-juvenil e literatura que circulavam nas escolas brasileiras, estabelecendo a educação indígena como um forma de compreensão do mundo ao mesmo tempo em que realiza críticas implícitas à formas de educação ocidental.

Esse aspecto relativo à autoria merece ênfase. A condição de minoria étnico-racial (ou de gênero) de um(a) autor(a) não é condição suficiente para elaboração de um discurso de promoção da diversidade. No entanto, o livro em questão dá mostras que autores indígenas (e negros) escrevendo sobre seu povo demonstram ter maior competência e segurança na descrição de seus costumes e cultura. Não é condição suficiente, mas muitas vezes revela-se como condição necessária (mesmo considerando como uma não exclusividade). 
Na obra "Ulomma" observam-se diversos aspectos significativos. O tratamento estético cuidadoso é bastante diverso das imagens repletas de estereotipia descritas em outros estudos (ROSEMBERG, 1985) e se relaciona com os papéis de reis, rainhas, príncipes e princesas exercidos por personagens negros(as) nos contos. A possibilidade de identificação com tais personagens, num momento de estruturação do imaginário que é a infância, tem sido reclamada por ativistas e pesquisadoras como formadora de uma identidade "não-colonial" de crianças negras, crianças estas que necessitam se identificar e valorizar a sua ancestralidade para que se oportunize a superação de relações de assimetria entre diferentes segmentos étnicos, com positivação da cultura e estética negra.

A negação ao imaginário racista que propõe branco(a) como relacionado à beleza e negro à feidade, também é contraposta pela obra. Além disso, há o fato de os personagens negros(as) serem protagonistas, exercendo papéis de narradores, ativos nas tramas, enfim, com a construção do personagem do negro tendo sido mais complexa, propiciando a superação das caricaturas tão comuns.

Os critérios tomemos os critérios arrolados por Araújo e Silva (2012) para avaliação do potencial de narrativas de livros de literatura infantil atuarem em prol da educação das relações étnico-raciais, a obra Ulomma, a casa das mulheres e outros contos apresenta a todos de forma positiva:

Presença e importância de personagens negras; se personagens principais; grau de ação na trama; uso de linguagem; se narradoras/es; ilustrações com valorização de aspectos fenotípicos ou com uso de símbolos relacionados com africanidades; temas relativos à história ou cultura africana ou africana da diáspora; qualidade estético literária; temas relativos a vivências de personagens africanas ou africanas da diáspora; ausência de estereótipos nos textos e nas ilustrações; ausência de hierarquias entre personagens brancas e negras; não presença da/o branca/o como representante exclusivo de humanidade (branquidade normativa). (ARAUJO e SILVA, 2012, p. 211).

A análise qualitativa de determinadas obras ajuda assim a compreender os resultados quantitativos, pois por detrás de indicadores por vezes menos acentuados na comparação com outras pesquisas, capta-se como o acervo em específico, que é tratado como amostra dos acervos do PNBE, estabelece lugares definidos para os personagens negros e indígenas. $\mathrm{Ou}$ 
seja, o direito à existência é reconhecido, mas se a situação a ser tratada é a própria diversidade étnico-racial. Fora desse contexto, negros e indígenas praticamente não existem.

\section{Considerações finais}

Ao fazer um balanço dos resultados, cotejamos os observados no estudo com aqueles destacados dos estudos anteriores de Rosemberg (1985); Pisa (1998) e Bazilli (1999), assim como com a literatura da área disponível. A pesquisa captou algumas mudanças e diversas permanências nas relações entre personagens brancas de um lado, negras e indígenas de outro. Observou a presença de narradoras negras e indígenas, com aumento em relação as pesquisas anteriores, embora ainda em proporção inferior a brancas; o surgimento de personagens negras e indígenas em contextos familiares; aumento relativo de personagens femininas negras; não incidência de formas estereotipadas de personagens negras e baixa incidência de personagens indígenas. Não foram observadas as características apontadas por Rosemberg (1985) de associação da cor negra a personagens más, nem da comparação de indígenas e negros a animais. A associação com sexualidade exacerbada observada por Pisa (1998) também não esteve presente na amostra.

Por outro lado, diversas formas de hierarquia étnico-racial se mantiveram. A personagem branca continuou sendo a representante "natural" da espécie humana. A subrepresentação de personagens negras e indígenas se mantiveram. A maior complexidade de personagens brancas em relação a negros e indígenas apresentou dados contraditórios. Algumas características como maior individualidade e unicidade de personagens brancas em comparação com indígenas e negras, se mantiveram. Observou-se tendência a produzir histórias voltadas a criança branca; a naturalização das desigualdades étnico-raciais; o silêncio se manifestando pela ausência de informações sobre personagens negras ou indígenas.

A sub-representação de personagens negras em textos e ilustrações é característica apontada em um conjunto grande de pesquisas (ROSEMBERG, 1985; BAZILLI, 1999; LIMA, 1999; GOUVÊA, 2005; KAERCHER, 2006; FERREIRA, 2008; DEBUS, 2010). O branco continua sendo representado como representante da espécie (ROSEMBERG, 1985; BAZILLI, 1999; FERREIRA, 2008; ARAUJO, 2010). A literatura infanto-juvenil parece estar promovendo o fortalecimento da hegemonia branca, visto que o branco foi o personagem mais bem caracterizado e enfocado nas obras, fato que demanda maiores reflexões para que se evitem 
comportamentos racistas perante aqueles que fogem ao padrão estabelecido. Tal situação se agrava se analisarmos que o público a quem se destinam as obras do PNBE, eminentemente, crianças em idade escolar, com a Escola podendo contribuir na difusão de atitudes preconceituosas ao invés de cumprir o papel de formar para a igualdade e o respeito à diferença.

De uma forma geral pode-se interpretar que os resultados da pesquisa confirmam o mito da democracia racial, com a literatura infanto-juvenil promovendo a discriminação de forma velada, mas ainda atuante, sem que o preconceito fique evidente, recriando situações de discriminação vividas cotidianamente e inclusive se posicionando de forma similar. Ao manter relações de dominação sem que o tema seja discutido, oportuniza-se a perpetuação das desigualdades vivenciadas por negros e indígenas.

As mudanças observadas podem ser caracterizadas como relativamente tênues, comparando o presente estudo com estudos anteriores.

Por exemplo, tendo havido melhor caracterização familiar do personagem negro. Nas ilustrações percebe-se maior cuidado nos traços, com os desenhos não sendo estereotipados nem, tampouco, alheios às culturas africanas. Percebe-se, todavia, que esse tratamento estético diferenciado ocorreu somente em uma obra da amostra. E, igualmente, num acervo de 20 obras, apenas uma trouxe o personagem negro como protagonista.

Evidencia-se assim que o racismo não tem sido temática discutida, mas sim reforçada pela quase ausência do negro na literatura (em geral) ou, ainda, pela sua apresentação de forma superficial e muitas vezes estereotipada, com as relações assimétricas entre brancos e nãobrancos sendo ainda mais evidentes no tocante à menina negra.

A análise demonstrou que apesar de haver no Brasil o mito de uma democracia racial, ainda se faz presente o preconceito que atua no sentido de estigmatizar grupos de pessoas cujas características não são tomadas como 'norma'. A branquidade normativa, ainda que encoberta por um discurso oficial de igualdade, permanece, não só nas relações concretas, mas também em plano simbólico, conforme analisado.

Apesar da atenuação de uma forma preconceituosa mais evidente no tratamento dos personagens, observa-se que o enfoque a determinados atributos confirma a percepção da 'diferença' enquanto 'desvio'. Assim, o homem, branco e adulto se faz modelo, numa perspectiva branqueadora, com marcas sexistas e, em menor medida, sob uma visão adultocêntrica. Araú- 
jo (2015) argumentou em favor da necessidade de se propor ações que promovam a melhoria do PNBE tanto no movimento de seleção das obras, para atender aos critérios de diversidade, quanto ao que se refere a utilização destas na escola, principal entreposto do objeto livro. Nossas conclusões estão em acordo com as proposições da autora, em favor da exploração da literatura em toda sua riqueza estética e força conceitual, ou seja, de forma crítica, reflexiva e questionadora com todos os segmentos humanos devendo ser representados em seu interior, num processo de respeito e acolhimento da 'diferença' que nos dá identidade.

\section{Referências}

ARAUJO, Débora Oyayomi Cristina de. Relações raciais, discurso e literatura infantojuvenil. Dissertação (Mestrado em Educação), Universidade Federal do Paraná, 2010.

ARAUJO, Débora Oyayomi Cristina de; SILVA, Paulo Vinicius Baptista da. Diversidade étnico-racial e a produção literária infantil: análise de resultados. In: BENTO, Maria Aparecida Silva (Org.). Educação infantil, igualdade racial e diversidade: aspectos políticos, jurídicos, conceituais. São Paulo: Centro de Estudos das Relações de Trabalho e Desigualdades - CEERT, 2012, p. 194-220.

ARAÚJO, Débora Oyayomi Cristina de. Literatura infanto-juvenil e Política Educacional: Estratégias de Radicalização No Programa Nacional biblioteca na Escola (PNBE). Tese (Doutorado em Educação), Universidade Federal do Paraná, 2010.

BAZILLI, Chirley. Discriminação contra personagens negros na literatura infanto-juvenil brasileira contemporânea. Dissertação (Mestrado em Psicologia Social). Pontifícia Universidade Católica de São Paulo, 1999.

BONIN, Iara Tatiana. Literatura infantil de autoria indígena: diálogos, mesclas, deslocamentos. Currículo sem Fronteiras, v.12, n.1, p. 36-52, Jan/Abr 2012.

DALCASTAGNÈ, Regina. A personagem do romance brasileiro contemporâneo: 1990-2004. Estudos de Literatura Brasileira Contemporânea. N. ${ }^{\circ} 26$, Brasília, julho-dezembro de 2005, p. $13-71$.

DEBUS, Eliane S. D. A literatura Infantil e a temática africana e afro-brasileira. Nação escola n². Editora Atilénde. Abril 2010.

DUARTE, Eduardo A. Literatura afro-brasileira: um conceito em construção. Estudos de literatura brasileira contemporânea. Brasília, n. 31, jan./jun. 2008, p. 11-23.

ESCANFELLA, Célia Maria. Construção social da infância e literatura infanto-juvenil brasileira contemporânea. São Paulo: Dissertação de mestrado (Psicologia Social — PUC/SP), 1999. 
ESCANFELLA, Célia Maria. Literatura infanto-juvenil brasileira e religião: Uma proposta de interpretação ideológica da socialização. São Paulo: Tese de doutoramento (Psicologia Social — PUC/SP), 2006.

FERREIRA, Leda Cláudia da Silva. A personagem do conto infanto-juvenil brasileiro contemporâneo: uma análise a partir de obras do PNBE/2005. Dissertação (Mestrado em Literatura Brasileira). Universidade de Brasília — UnB, 2008.

FRANÇA, Luiz Fernando de. Personagens negras na literatura infantil brasileira: da manutenção à desconstrução do estereótipo. Dissertação (Mestrado em Estudos de Linguagem). Cuiabá: Universidade Federal do Mato Grosso, 2006.

KAERCHER, Gládis Elise Pereira da Silva. O mundo na caixa: gênero e raça no Programa Nacional de Biblioteca da Escola - 1999. Tese (Doutorado em Educação). Porto Alegre: Universidade Federal do Rio Grande do Sul.

GOUVÊA, Maria Cristina S. de. Imagens do negro na literatura infantil brasileira: análise historiográfica. Educação e Pesquisa, São Paulo, v. 31, n. ${ }^{\circ}$ 1, p. 77-89, janeiro/abril, 2005.

LIMA, Heloisa Pires de. Personagens negros: um breve perfil na literatura infanto-juvenil. In: MUNANGA, Kabengele (Org.). Superando o racismo na escola. Brasília: Ministério da Educação, Secretaria de Educação Continuada, Alfabetização e Diversidade, 1999, p. 101-116.

NOGUEIRA, Dione M. S. Um olhar sobre discriminações sexuais na literatura infantojuvenil brasileira contemporânea. Dissertação. São Paulo: Pontifícia Universidade Católica de São Paulo, 2001.

OLIVEIRA, Veridiane Cintia de Souza. Educação das relações étnico-raciais e estratégias ideológicas no acervo do PNBE 2008 para educação infantil. Dissertação (Mestrado em Educação). Universidade Federal do Paraná, 2010.

PIZA, Edith Pompeu. O caminho das águas: Estereótipos de personagens por escritoras brancas. São Paulo: Editora da Universidade de São Paulo: Com-Arte, 1998.

ROSEMBERG, Fúlvia. Literatura infanto-juvenil e ideologia. São Paulo: Global, 1985.

ROSEMBERG, Fúlvia. A criança pequena e o direito à creche no contexto dos debates sobre infância e relações raciais. In: BENTO, Maria Aparecida Silva (Org.). Educação infantil, $i$ gualdade racial e diversidade: aspectos políticos, jurídicos, conceituais. São Paulo: Centro de Estudos das Relações de Trabalho e Desigualdades - CEERT, 2012, p. 11-46.

SILVA, Paulo Vinicius Baptista da. Desigualdades raciais em livros didáticos e literatura infanto-juvenil. In: Hilton Costa; Paulo Vinícius Baptista da Silva (Org.). Notas de História e Cultura Afro-Brasileiras. 1. ed. Ponta Grossa/Curitiba: Editora UEPG/Cátedra UNESCO de Cultura da Paz, 2007, v. 1, p. 159-190.

SILVA, Paulo Vinicius Baptista da. One More Story: Racial Relations and Stereotypes in Brazilian Literature. Diogenes (English ed.), v. 59, p. 168-180, 2014.

SILVA, Paulo Vinicius Baptista da. Relações raciais em livros didáticos: estudo sobre negros e brancos em livros de Língua Portuguesa. Belo Horizonte: Autêntica, 2008. (Coleção Cultura Negra e Identidade). 
SILVA, Paulo Vinicius Baptista; SANTOS, Wellington Oliveira dos; ROCHA, Neli Gomes. Personagens negros e brancos em peças publicitárias publicadas em jornais paranaenses. Cadernos NEPRE, v. 5, p. 7-24, 2007.

VENÂNCIO, Ana Carolina Lopes. Literatura infanto-juvenil e diversidade. Dissertação (Mestrado em Educação) — Universidade Federal do Paraná, 2009.

Recebido em 8 de agosto de 2015.

Aceito em 14 de setembro de 2015. 
